PREPARED FOR THE U.S. DEPARTMENT OF ENERGY, UNDER CONTRACT DE-AC02-76CH03073

PPPL-3881

PPPL-3881

UC-70

NSTX High Field Side Gas Fueling System

by

H.W. Kugel, M. Anderson, G. Barnes, M. Bell, W. Blanchard, L. Dudek,

D. Gates, R. Gernhardt, R. Maingi, D. Mueller, T. Provost,

R. Raman, V. Soukhanovskii, and J. Winston

October 2003
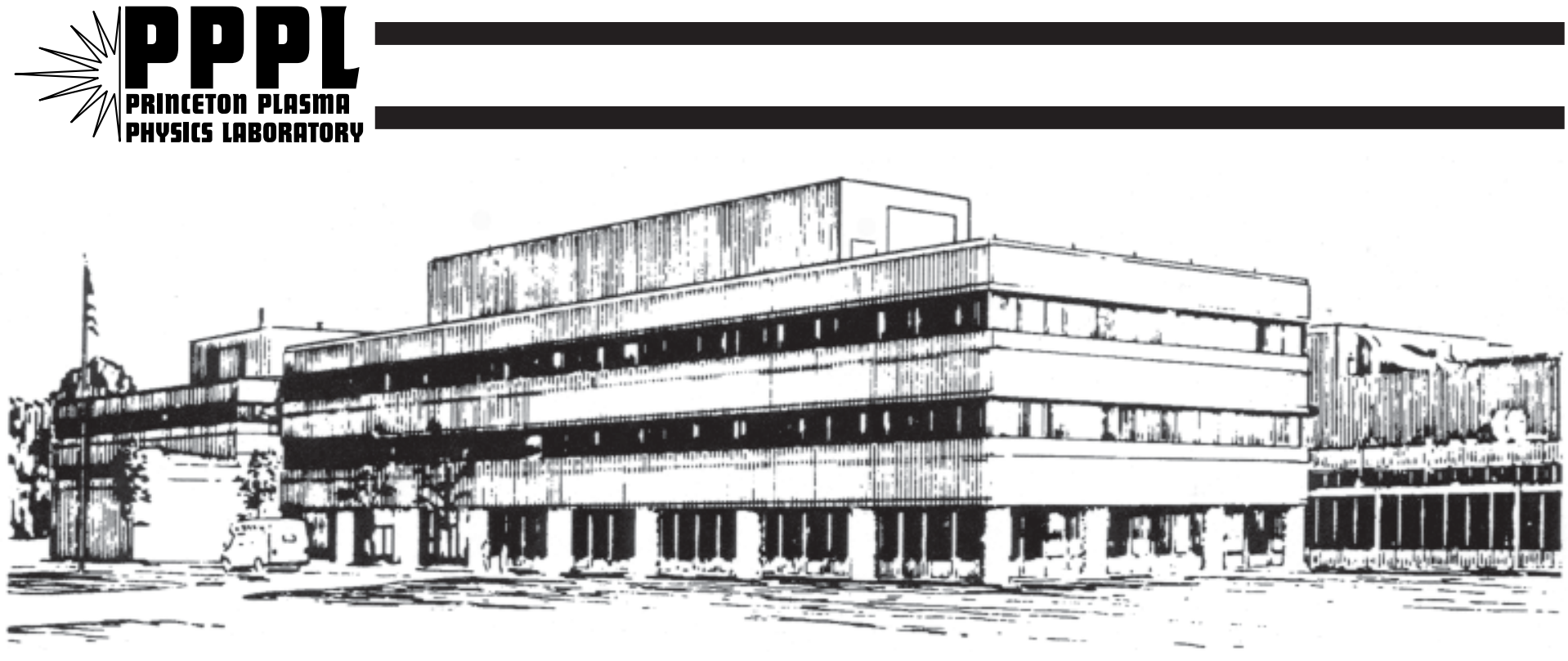

PRINCETON PLASMA PHYSICS LABORATORY PRINCETON UNIVERSITY, PRINCETON, NEW JERSEY 


\section{PPPL Reports Disclaimer}

This report was prepared as an account of work sponsored by an agency of the United States Government. Neither the United States Government nor any agency thereof, nor any of their employees, makes any warranty, express or implied, or assumes any legal liability or responsibility for the accuracy, completeness, or usefulness of any information, apparatus, product, or process disclosed, or represents that its use would not infringe privately owned rights. Reference herein to any specific commercial product, process, or service by trade name, trademark, manufacturer, or otherwise, does not necessarily constitute or imply its endorsement, recommendation, or favoring by the United States Government or any agency thereof. The views and opinions of authors expressed herein do not necessarily state or reflect those of the United States Government or any agency thereof.

\section{Availability}

This report is posted on the U.S. Department of Energy's Princeton Plasma Physics Laboratory Publications and Reports web site in Fiscal Year 2004. The home page for PPPL Reports and Publications is: http://www.pppl.gov/pub_report/

DOE and DOE Contractors can obtain copies of this report from:

U.S. Department of Energy

Office of Scientific and Technical Information

DOE Technical Information Services (DTIS)

P.O. Box 62

Oak Ridge, TN 37831

Telephone: (865) 576-8401

Fax: (865) 576-5728

Email: reports@adonis.osti.gov

This report is available to the general public from:

National Technical Information Service

U.S. Department of Commerce

5285 Port Royal Road

Springfield, VA 22161

Telephone: $1-800-553-6847$ or

(703) $605-6000$

Fax: (703) 321-8547

Internet: http://www.ntis.gov/ordering.htm 


\title{
NSTX High Field Side Gas Fueling System
}

\author{
H.W.Kugel, M.Anderson, G.Barnes, M.Bell, W.Blanchard, L.Dudek, D.Gates, R.Gernhardt, \\ R.Maingi ${ }^{\mathrm{a}}$, D.Mueller, T.Provost, R.Raman ${ }^{\mathrm{b}}$, V.Soukhanovskii, J.Winston \\ Princeton Plasma Physics Laboratory, Princeton, NJ 08543, USA \\ ${ }^{a}$ Oak Ridge National Laboratory, Oak Ridge TN, 37831, USA \\ ${ }^{\mathrm{b}}$ University of Washington, Seattle, WA,98195, USA
}

\begin{abstract}
Fueling NSTX plasmas with gas injected from the high field side (HFS) has produced earlier, more reliable transitions to the $\mathrm{H}$-mode, longer $\mathrm{H}$-mode durations, higher toroidal rotation, and higher edge $T_{e}$ compared with similar discharges using the low field side (LFS) gas fueling injectors. The HFS gas fueling system consists of a Center Stack midplane injector, and an injector at the inner, upper corner of the Center Stack. The challenging design and installation constraints for the HFS gas system involved placing the control components as close as possible to the machinevacuum interface, devising a special feed-through flange, traversing through vessel regions whose temperatures during bake-out range from $150 \mathrm{C}$ to $350 \mathrm{C}$, adapting the gas transport tubing size and route to the small instrumentation wire channels behind the existing graphite PFC tiles on the Center Stack, and providing output orifices shielded from excessive plasma power depositions while concentrating the output flow to facilitate fast camera viewing and analysis. Design, recent performance, and future upgrades will be presented.
\end{abstract}

\section{INTRODUCTION}

The National Spherical Torus Experiment (NSTX,) is evaluating the physics principles of spherical torus (ST) geometry, characterized by strong magnetic field curvature, high beta-toroidal, and close-wall passive plate stabilizers[1]. Fig.1 shows a schematic cross sectional view of NSTX. In the relatively brief operating time since first plasma in 1999, NSTX has achieved a $\beta_{\mathrm{T}}$ of $\sim 35 \%$ at $\mathrm{Ip}=1.2 \mathrm{MA}$ and $\mathrm{B}_{\mathrm{T}}=0.3 \mathrm{~T}$ using $6 \mathrm{MW}$ of $90 \mathrm{keV}$ neutral beam heating [2]. In the highest stored energy discharges $(280 \mathrm{~kJ})$, the central ion temperature was $\sim 3 \mathrm{keV}$ and the central electron temperature $\sim 1.4 \mathrm{keV}$ [2]. H-modes have been accessed routinely with confinement times up to $120 \mathrm{~ms}$ [3]. High Harmonic Fast Wave heating has achieved central electron temperatures of $\mathrm{T}_{e}>3 \mathrm{keV}$ and discharges which exhibit apparent internal electron transport barriers [4]. In addition, Coaxial Helicity Injection (CHI) has been under investigation as a non-inductive current drive technique has achieved toroidal currents of $390 \mathrm{kA}$ [5].

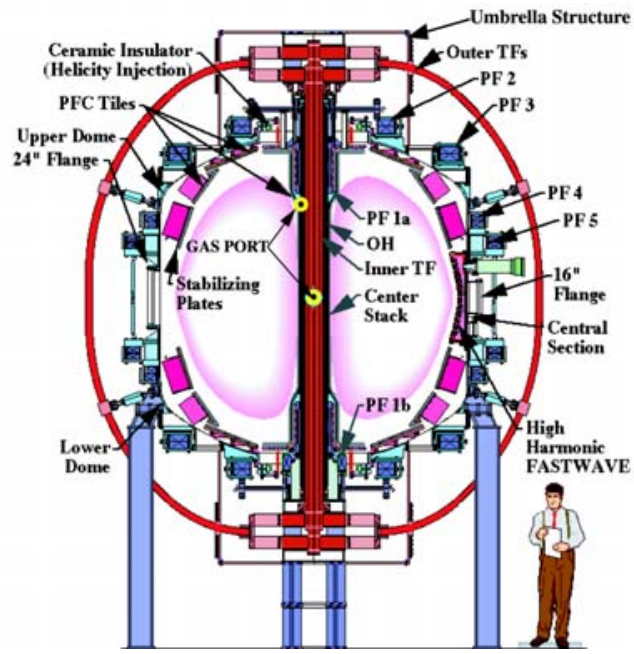

Fig.1. Schematic cross section of NSTX.

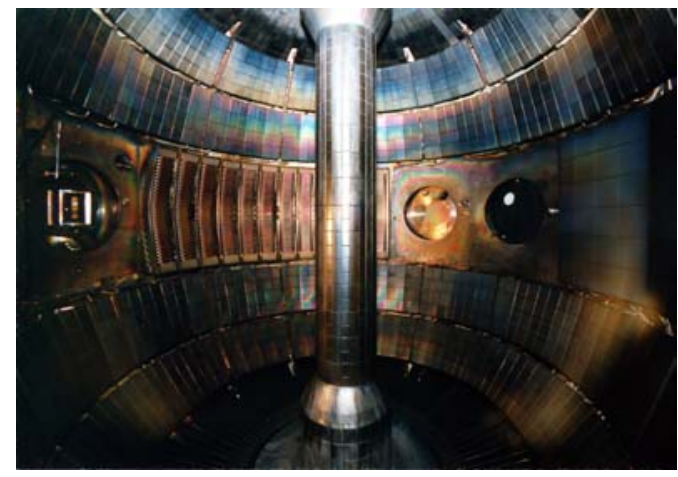

Fig.2. Photo of NSTX interior.

As this work progressed, it became evident that the outer vessel, low field side (LFS) gas fueling system used for the first NSTX plasmas was no longer adequate for providing sufficient plasma density control and for improving H-mode access. Coincident with this growing need, the Mega Amp Spherical Torus (MAST) demonstrated the effectiveness of fueling $\mathrm{H}$-mode plasmas with gas injected from the high field side (HFS) [6]. This motivated the adoption of a similar system for NSTX. 
The NSTX HFS gas fueling system consists of 2 gas injection assemblies with injection points at the Center Stack (CS) midplane, and the upper corner (shoulder injector) of the CS (Fig.1). When used to fuel NSTX plasmas, the CS midplane HFS injector has produced earlier, more reliable transitions to the $\mathrm{H}$-mode, longer H-mode durations, higher toroidal rotation, and higher edge $T_{e}$ in comparison to similar discharges using the LFS gas fueling injectors [3]. The 2nd injector at the CS shoulder was installed to give additional fueling control.

\section{DESIGN}

Installation of a controlled HFS fueling system for low aspect ratio geometries is difficult to implement. This is due to the typically small space available at the inner wall that prevents the installation of fast, controllable valves at the output orifices. Under these constraints, the only available recourse has been to install long gas transport tubes of small diameter from the fast controllable valves located outside of the vessel. This results in the gas flow being restricted by the impedance of the gas transport tube yielding relatively slow fuel delivery rates and time constants that are longer than desired. At plenum pressures of a few bar, the initial gas flow in the tube is in the viscous flow range, which for a tube of internal diameter (D) and pressure (P) results in a flow rate dependence proportional to $\sim \mathrm{D}^{4} \mathrm{P}^{2}$. Hence, maximizing the tube internal diameter, if possible, yields a strong increase in flow rate.

In addition to the limited space available along the $\mathrm{CS}$, the installation of the HFS gas fueling system on NSTX required resolving many challenging design and installation constraints. First, space had to be located as close as possible to the machine-vacuum

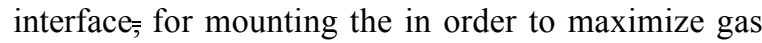
conductance to the output region. Two adjacent 3.375 inch vacuum flanges on the upper Center Stack Inner Divertor region at the inner most region of the upper dome were selected as the feedthroughs for the gas delivery lines. Since the Upper and Lower Umbrella structures at the top and bottom of the vessel (Fig.1) are highly congested with hardware that includes the TF busses as they enter the CS, the two gas injection assemblies had to be mounted on the outside of the Upper Umbrella at the closest point to the feedthroughs approximately $1 \mathrm{~m}$ away. Fig. 3 shows the HFS gas injection assembly and components. The valve board base consists of $1.27 \mathrm{~cm}$ thick G-11 to maintain electrical isolation of the components. The assembly consists of an air actuated torus isolation valve, injection valve, fill valve, and plenum. The isolation valve allows for maintenance of the system

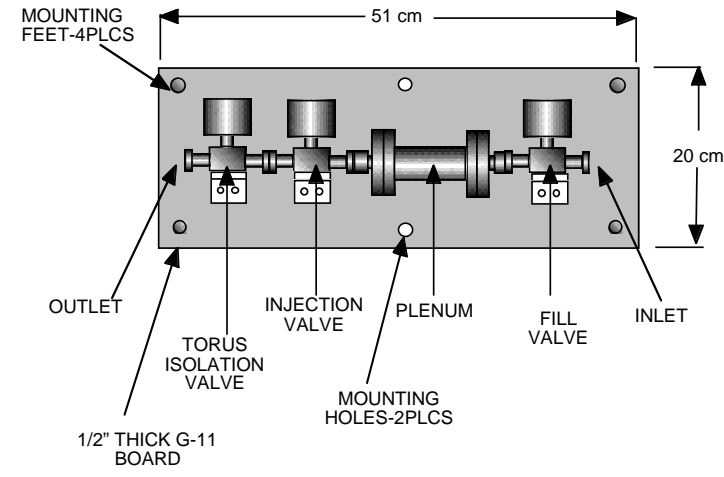

Fig.3. CS gas injection assembly.

and the fill valve isolates the plenum at a precisely known pressure and therefore a well defined amount of fuel gas prior to each discharge. The injection valve is a full open or closed valve that is timed to open at a pre-programmed time during the discharge. Calibration tests were run to measure both the time constants and flow rates of the system for various plenum pressures in order to optimize the fueling for HFS discharges.

A special gas tube feed-through for the vessel flange was designed to accommodate installation, possible leak maintenance, and thermal stresses during vessel bakeout. The design had to accommodate thermal effects as the gas transport tubes traversed through vessel regions whose temperatures during bake-out ranged from $150^{\circ} \mathrm{C}$ to $350^{\circ} \mathrm{C}$. Therefore, it was desirable to select sufficiently ductile internal gas transport tubing, with the largest internal diameter (ID) allowed by the only available tubing route through the small instrumentation wire channels on back face of the existing graphite plasma facing components (PFC) tiles on the CS. Additionally, it was necessary to provide an output orifice shielded from excessive plasma power depositions while ensuring a direct line of sight from the orifices to the plasma region, and thereby concentrating the output flow to facilitate fast camera data acquisition and analysis.

At the vessel flange, the external gas transport tube is welded to a standard 1.33 inch OD mini conflat flange which is fastened to a 3.375 inch to 1.33 inch zero-length adapter flange. On the inside face of the 3.375 inch OD flange, a weldment supports the beginning of the internal gas transport tube which carries the gas to behind the existing graphite PFC tiles on the Center Stack. This two part feedthrough arrangement was designed to allow for maintenance and leak checking of the system and gas feed line if required. Fig. 4 is a photo showing the gas transport tube weld joint on the vacuum side of this flange and 


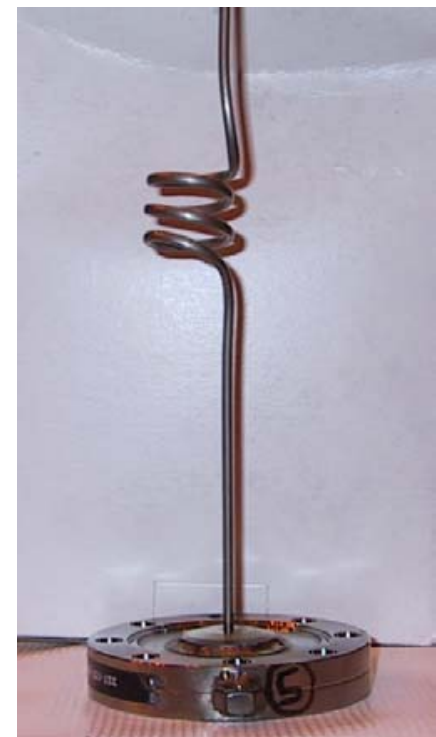

Fig.4. Photo showing the gas transport tube weld joint on the vacuum side of this flange and nearby strain relief coil.

the nearby strain relief coil in the gas transport tube which accommodates the $350^{\circ} \mathrm{C} \mathrm{CS}$ temperature and the $150{ }^{\circ} \mathrm{C}$ flange temperature during vessel bakeout The tubing shown in Fig. 4 is $6.35 \mathrm{~mm}$ O.D., $4.57 \mathrm{~mm}$ I.D. fully annealed 321-SS with Ti additive for ductility. This ductility was essential for installation of the tubing through the confined geometry of the vessel interior.

\section{INSTALLATION}

The installation was dominated by the constraints imposed by the graphite PFC tiles on the CS. These graphite tiles, which range in thickness from $5 \mathrm{~cm}$, on the inner horizontal divertor, to only $1.27 \mathrm{~cm}$, on the

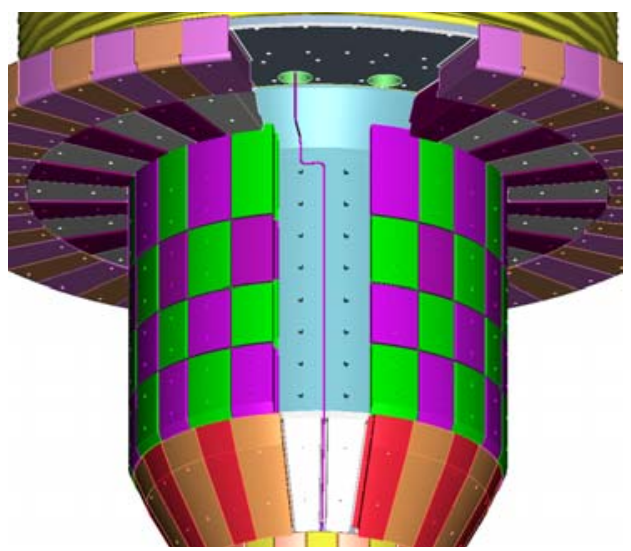

Fig.5. Schematic of a gas transport tube as it enters NSTX. midplane, are fastened with hardware that prevented convenient modification for gas transport tubing. This restricted the available space to the narrow instrumentation wire channels which are along the tile edges in the divertor region, and in the tile centers in the midplane region. These channels behind the tiles typically contain instrumentation wiring for thermocouples, Langmuir probes, and magnetic sensors. Fig. 5 is a schematic of the gas transport tube as it enters the vessel in the upper horizontal divertor, and undergoes three $90^{\circ}$ bends as it proceeds downward toward the narrower midplane region. Fig.6 shows the gas transport tube during installation along the CS near the midplane.

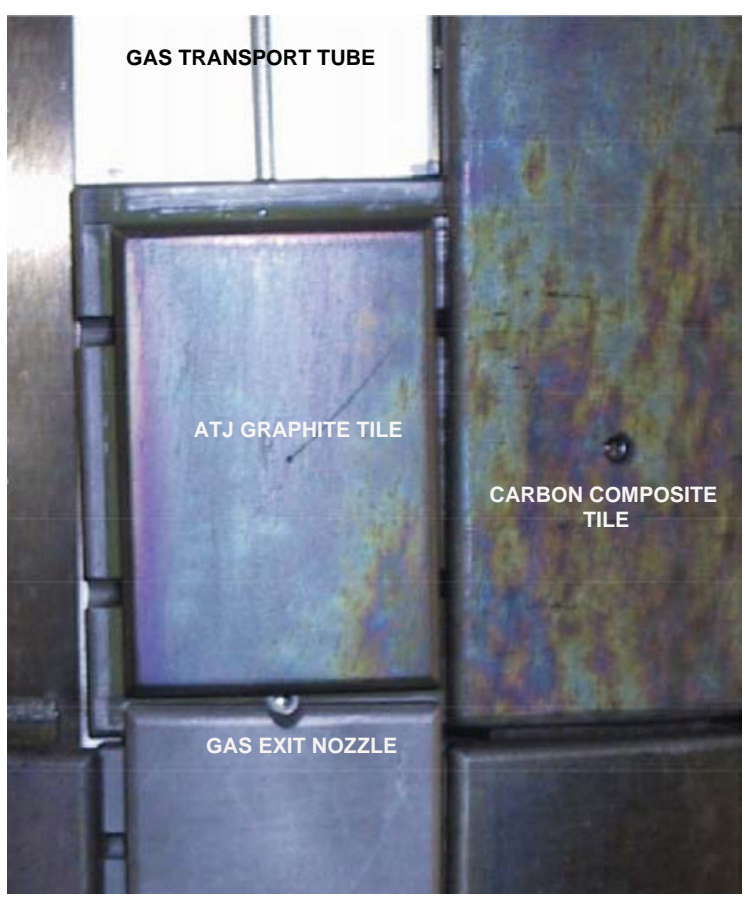

Fig.6. Photo of gas transport tube installation along CS near the midplane with some tiles removed.

At the top of Fig. 6, a graphite tile has been removed and the the gas transport tube is seen against a white background as it enters the instrumentation wiring channel on the back face of the midplane tile. The gas transport tube ends at the midplane where it is pressfit into a 304-SS elbow which provides the exit nozzle. The press-fit exit nozzle provides a simple, low conductance seal with the tube that allows for easy changes in the nozzle configuration. Additionally, the nozzle is recessed from the surface of the graphite PFCs to limit the plasma from impinging on the unit during discharges. 


\section{PERFORMANCE}

Fig. 7 shows a comparison of the waveforms of the total deuterium gas injected into NSTX in the absence of plasma versus time using the HFS CS

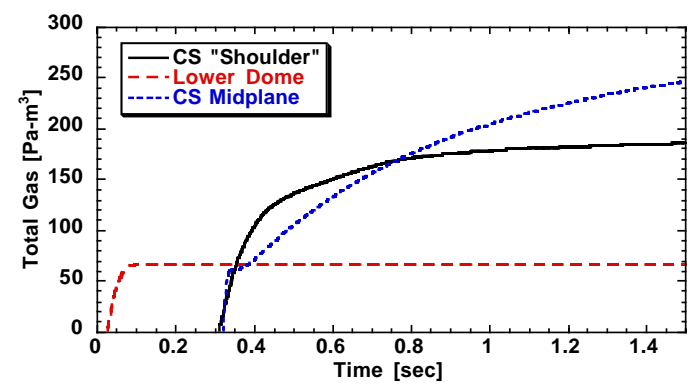

Fig. 7. Comparison of total injected gas $\left(\mathrm{Pa}-\mathrm{m}^{3}\right)$ vs time for NSTX gas injectors.

midplane and CS shoulder injectors and gas injected from the lower dome divertor region. The rise of the HFS signals is later indicating a longer time constant than the Lower Dome signal due to their longer and smaller diameter gas transport tubes. The faster rate of rise of the HFS CS shoulder injector signal relative to that of the CS midplane injector is due to both the larger tube ID and shorter tube length. Fig.9 shows waveforms of the plasma current $\left(\mathrm{I}_{\mathrm{p}}\right), \mathrm{H}$-alpha luminosity $\left(\mathrm{H}_{\alpha}\right)$,electron densities $\left(\mathrm{n}_{\mathrm{e}}\right)$, stored energy $\left(\mathrm{W}_{\mathrm{MHD}}\right)$, and confinement time $\left(\tau_{\mathrm{E}}\right)$ for high performance $800 \mathrm{KA}, 10 \mathrm{MW}$, NBI heated H-mode discharge with combined HFS and LFS fuelling. The HFS CS midplane injector gives

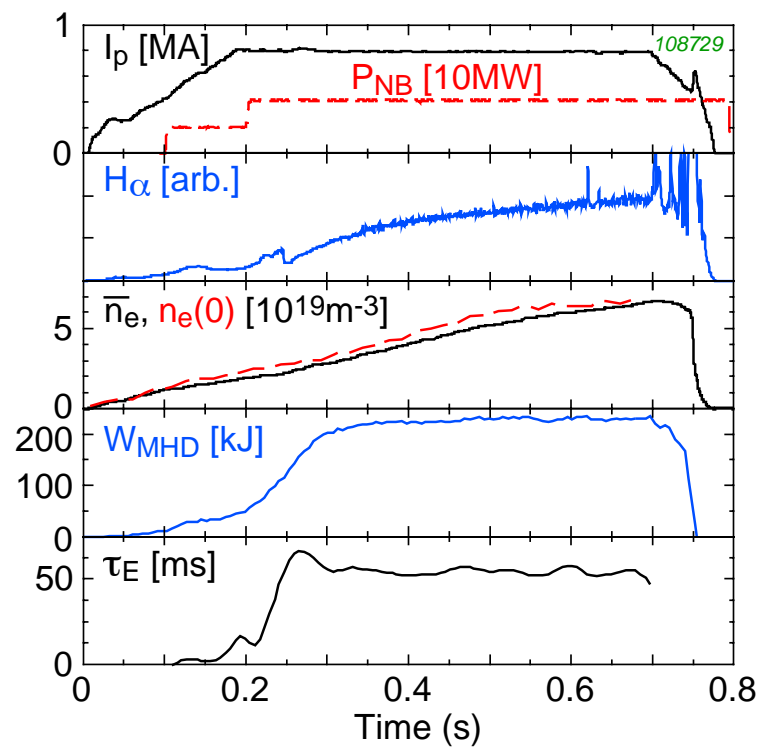

Fig.9. Plasma waveforms during $\mathrm{H}$-mode. large initial flow but then gives a continuing lower flow which contributes to the density rise. The $\mathrm{H}_{\alpha}$ signal exhibits a strong drop as the discharge transitions into the $\mathrm{H}$-mode at $0.24 \mathrm{~s}$ and the stored energy rises and remains relatively constant during the $I_{p}$ flattop. The ensemble of the 2 CS gas injectors, the lower dome and outer wall midplane injectors provide a poloidal array of gas injectors. An investigation of the dependence of the $\mathrm{H}$-mode characteristics on the poloidal location of fueling was started in 2003. Initial results indicate that for Lower Single Null diverted plasmas, the easiest access to the $\mathrm{H}$-mode was provided with the CS midplane injector, and for Double Null diverted plasmas, the CS midplane and CS shoulder injectors give similar responses. Work is in progress to further investigate these fueling characteristics.

\section{SUMMARY AND CONCLUSIONS}

The installed HFS gas injection system improved both the reproducibility and longevity of the H-mode. This upgrade in performance is a direct and visible result of adding HFS fueling to NSTX operating capability. The installation of the HFS gas fueling system required resolving many challenging design and installation constraints. Future work will focus on determining if adding additional poloidal HFS injectors will be required, and exploring methods for improving the response times and control of these injection systems.

\section{ACKNOWLEDGMENT}

This is work supported by U.S. DOE Contracts DE-AC02-76CH03073 and DE-AC05-00OR22725, and Grant DE-FG02-99ER54519.

\section{REFERENCES}

[1] J. E. Menard, et al., "Beta-limiting MHD Instabilities in Improved Performance NSTX Spherical Torus Plasmas", Nucl. Fusion, 43 (2003) 330.

[2] D. Gates, et al., "High Beta, long Pulse, Bootstrap Sustained Scenarios on the national Spherical Torus Experiement (NSTX)", Phys. plasmas, 10 (2003) 1659.

[3] R. Maingi, et. al., "H-mode Research in NSTX", Nucl. Fusion in press, 9/03.

[4] E. J. Synakowski, "Initial Studies of Core and Edge Transport of NSTX Plasmas", Plasma Phys. Control. Fusion, 44, (2002) A165.

[5] R. Raman, et al., "Non-inductive current Generation in NSTX using Coaxial Helicity Injection", Nucl. Fusion 41, (2001) 1081.

[6] A. R. Field, "H-mode Plasmas in the MAST Spherical Tokamak", Plasma Phys. Control. Fusion, 44, (2002) A113. 


\section{External Distribution}

Plasma Research Laboratory, Australian National University, Australia

Professor I.R. Jones, Flinders University, Australia

Professor João Canalle, Instituto de Fisica DEQ/IF - UERJ, Brazil

Mr. Gerson O. Ludwig, Instituto Nacional de Pesquisas, Brazil

Dr. P.H. Sakanaka, Instituto Fisica, Brazil

The Librarian, Culham Laboratory, England

Mrs. S.A. Hutchinson, JET Library, England

Professor M.N. Bussac, Ecole Polytechnique, France

Librarian, Max-Planck-Institut für Plasmaphysik, Germany

Jolan Moldvai, Reports Library, Hungarian Academy of Sciences, Central Research Institute for Physics, Hungary

Dr. P. Kaw, Institute for Plasma Research, India

Ms. P.J. Pathak, Librarian, Institute for Plasma Research, India

Ms. Clelia De Palo, Associazione EURATOM-ENEA, Italy

Dr. G. Grosso, Instituto di Fisica del Plasma, Italy

Librarian, Naka Fusion Research Establishment, JAERI, Japan

Library, Laboratory for Complex Energy Processes, Institute for Advanced Study, Kyoto University, Japan

Research Information Center, National Institute for Fusion Science, Japan

Dr. O. Mitarai, Kyushu Tokai University, Japan

Dr. Jiangang Li, Institute of Plasma Physics, Chinese Academy of Sciences, People's Republic of China

Professor Yuping Huo, School of Physical Science and Technology, People's Republic of China

Library, Academia Sinica, Institute of Plasma Physics, People's Republic of China

Librarian, Institute of Physics, Chinese Academy of Sciences, People's Republic of China

Dr. S. Mirnov, TRINITI, Troitsk, Russian Federation, Russia

Dr. V.S. Strelkov, Kurchatov Institute, Russian Federation, Russia

Professor Peter Lukac, Katedra Fyziky Plazmy MFF UK, Mlynska dolina F-2, Komenskeho Univerzita, SK-842 15 Bratislava, Slovakia

Dr. G.S. Lee, Korea Basic Science Institute, South Korea

Institute for Plasma Research, University of Maryland, USA

Librarian, Fusion Energy Division, Oak Ridge National Laboratory, USA

Librarian, Institute of Fusion Studies, University of Texas, USA

Librarian, Magnetic Fusion Program, Lawrence Livermore National Laboratory, USA

Library, General Atomics, USA

Plasma Physics Group, Fusion Energy Research Program, University of California at San Diego, USA

Plasma Physics Library, Columbia University, USA

Alkesh Punjabi, Center for Fusion Research and Training, Hampton University, USA

Dr. W.M. Stacey, Fusion Research Center, Georgia Institute of Technology, USA

Dr. John Willis, U.S. Department of Energy, Office of Fusion Energy Sciences, USA

Mr. Paul H. Wright, Indianapolis, Indiana, USA 
The Princeton Plasma Physics Laboratory is operated by Princeton University under contract with the U.S. Department of Energy.

\author{
Information Services \\ Princeton Plasma Physics Laboratory \\ P.O. Box 451 \\ Princeton, NJ 08543
}

Phone: 609-243-2750

Fax: 609-243-2751

e-mail: pppl_info@pppl.gov

Internet Address: http://www.pppl.gov 